\title{
The Use of Gentamicin-Impregnated Collagen Sponge for Reducing Surgical Site Infection after Spine Surgery
}

\author{
Jin-Sol Han, Se-Hoon Kim, Sung-Won Jin, Seung-Hwan Lee, Bum-Joon Kim, \\ Sang-Dae Kim, Dong-Jun Lim \\ Department of Neurosurgery, Korea University Ansan Hospital, Korea University College of Medicine, Ansan, Korea
}

\begin{abstract}
Objective: Surgical site infection (SSI) is the one of the most frequent complications in hospitalized patients, and it extends hospital stays and causes extra morbidities. To reduce SSI after spine surgery, we applied the gentamicin-impregnated collagen sponge (Collatamp G) during the operation and analyzed the results retrospectively.

Methods: Between October 2012 and December 2015, we collected data who applied the Collatamp G in spine surgery at a single institution. Demographic data of patients and another possible risk factors of SSI were also included, and we assessed the correlation between the risk factors and the developing of SSI by reviewing electronic medical records retrospectively.

Results: Three percent of all patients (10 of 280) developed the SSI and only $0.8 \%$ of patients who applied Collatamp G developed SSI (1 of 119). Otherwise, $5 \%$ of patients who did not apply Collatamp $G$ developed SSI ( 9 of 161$)(p=0.034)$. We also analyzed the correlation between SSI and other potential risk factors but nothings showed statistical correlation with SSI.

Conclusion: In this study, there were statistically significant results that SSI rate was decreased in the group of patients using Collatamp G in spine surgery generally. However, further studies are required to resolve some limitations in the future.
\end{abstract}

Key Words: Gentamicin · Collagen · Surgical wound infection

\section{INTRODUCTION}

Surgical site infection (SSI) is one of the most frequent complications among the hospitalized patients. According to the previous studies, almost $3 \%$ of all postoperative patients suffer from wound infection after surgery. SSI extends hospital dates and recovery periods, and also causes extra morbidities ${ }^{4)}$.

SSI after spine surgery can also have distressing moments, so once recognized, urgent and definite cure is required to return the patient to the regular recovery course. Prevention of SSI is obviously better than cure for this disastrous complication, but SSI continues to arise even in the application of aseptic procedures and prophylactic antibiotics ${ }^{2}$.

As there are many ways to reduce SSI, we applied a gentamicin-impregnated collagen sponge (Collatamp G, ScheringPlough, Stockholm, Sweden) during the spine surgery. The

- Received: July 12, 2016 • Revised: August 22, 2016

- Accepted: August 25, 2016

Corresponding Author: Se-Hoon Kim

Department of Neurosurgery, Korea University Ansan Hospital, Korea

University College of Medicine, 123 Jeokgeum-ro, Danwon-gu, Ansan 15355, Korea

Tel: +82-31-412-5050, Fax: +82-31-412-5054

E-mail: sehoonkim.ns@gmail.com

@This is an open access article distributed under the terms of the Creative Commons Attribution Non-Commercial License (http://creativecommons.org/licenses/by-nc/4.0/) which permits unrestricted non-commercial use, distribution, and reproduction in any medium, provided the original work is properly cited.
Collatamp $\mathrm{G}$ is a topical appendage for intraoperative antibiotic prophylaxis and consists of a matrix of purified bovine collagen type I impregnated with $2.0 \mathrm{mg} / \mathrm{cm}^{2}$ gentamicin sulfate. This antibiotic is released by diffusion and enzymatic breakdown of the collagen sponge, presenting a strong concentration for at least 72 hours ${ }^{10}$. In this report, we performed a retrospective study to evaluate whether the Collatamp G reduces the incidence of SSI in patients after spine surgery.

\section{MATERIALS AND METHODS}

Between October 2012 and December 2015, we collected data from the electronic medical records of patients who applied the gentamicin-impregnated collagen sponge in spine surgery at a single institution. We excluded any patients that received spine surgery more than once, and any patients who already had infectious spinal diseases. Patients receiving multiple surgeries but on different sites were included in the study.

We collected the following information from the each patients: age at surgery, sex, diabetes mellitus status, smoking status, operation area (cervical, thoracic, or lumbar), operation level (1 level, 2 levels, or multiple levels), operation duration, surgical implantation, laboratory data and SSI. The primary endpoint was the development of any kind of wound infection within 1 month after spine surgery. We assessed the presence of SSI by reviewing electronic medical records of hospital dates and outpatient department follow-up. 


\section{Diagnosis of SSI}

Patients with SSI usually showed the signs and symptoms such as operation site pain, redness and/or swelling of the wound, or dehiscence with/without drainage of pus. If there were clear evidences of SSI, wound exploration and swab/aspiration culture were followed for diagnosis. However sometimes patients showed no specific signs or symptoms, even presenting fever was not common either, additional studies were required for accurate diagnosis.

Laboratory results and gadolinium-enhanced magnetic resonance image (MRI) were also used in the diagnosis of SSI. We supposed the patients with elevated values of erythrocyte sedimentation rate (ESR; normal range, $0-10 \mathrm{~mm} / \mathrm{hr}$ ) and C-reactive protein (CRP; normal range, $0-0.5 \mathrm{mg} / \mathrm{dL}$ ) would have infection at any site ${ }^{12)}$. The patients would show vague signs and symptoms or confusing laboratory results, gadolinium-enhanced MRI was used to differentiate the site of infection.

In this study, both symptomatic patients with visible wound problems and asymptomatic patients but showing abnormal laboratory results underwent gadolinium enhanced MRI and were analyzed for all the results to make diagnosis of SSI. If the visible wound problems needed surgical intervention, wound exploration and intraoperative swab culture was performed. If the wound was clean or additional surgical intervention was not necessary, ultrasound or computed tomog- raphy (CT) guided aspiration or tissue culture was performed for accurate diagnosis of SSI. If the result of intraoperative swab culture or aspiration culture was positive, the diagnosis of SSI was confirmed. Even though the result of the culture was negative, we could confirm the diagnosis when abnormal laboratory results and the enhancing area in gadolinium-enhanced MRI showed clear correlation with symptoms of patients.

\section{Antibiotics Prophylaxis and Postoperative Care}

Standard sterilization and preparation were routinely performed before spine surgery especially including antibiotics prophylaxis. Patients were given intravenous injection of 1 st generation cephalosporin 1 hour before skin incision. After surgery, all patients were given prophylactic intravenous injection of the same 1st generation cephalosporin till postoperative day (POD) 3 .

\section{Gentamicin-Impregnated Collagen Sponge}

The Collatamp G was available in $5 \times 5-\mathrm{cm}$ or $10 \times 10-\mathrm{cm}-$ sized sheets. The exact size of the Collatamp $G$ applied in the operation field was not recorded, but the Collatamp G was applied entirely or partially cut into small strips according to the size of the operation field in the level of the sheath or the subcutaneous layer during wound closure.

Table 1. The clinical manifestation and treatment of patients with surgical site infection

\begin{tabular}{|c|c|c|c|c|c|c|c|c|c|c|c|c|c|}
\hline №. & $\begin{array}{l}\text { Age } \\
\text { (yr) }\end{array}$ & Sex & $\begin{array}{l}\text { Diabetes } \\
\text { mellitus }\end{array}$ & Smoking & $\begin{array}{l}\text { Operation } \\
\text { area }\end{array}$ & $\begin{array}{c}\text { Operation } \\
\text { level }\end{array}$ & $\begin{array}{l}\text { Operation } \\
\text { duration } \\
\text { (min) }\end{array}$ & $\begin{array}{c}\text { Surgical } \\
\text { implantation }\end{array}$ & $\begin{array}{l}\text { Signs and } \\
\text { symptoms }\end{array}$ & $\begin{array}{l}\text { Laboratory } \\
\text { findings }\end{array}$ & Gulture results & $\begin{array}{c}\text { Wound } \\
\text { exploration and/or } \\
\text { implant removal }\end{array}$ & Antibiotics \\
\hline 1 & 44 & Male & Yes & No & Cervical & 1 Level & 105 & Yes & $\begin{array}{l}\text { Operation } \\
\text { site pain }\end{array}$ & Abnormal" & Negative & No & $\begin{array}{l}\text { Vancomycin } \\
\text { (Empirical) }\end{array}$ \\
\hline 2 & 45 & Female & Yes & No & Lumbar & 2 Levels & 315 & Yes & $\begin{array}{l}\text { Dehiscence } \\
\text { with pus }\end{array}$ & Abnormal & E. faecium & $\mathrm{E}+\mathrm{R}^{+}$ & $\begin{array}{l}\text { Ampicillin/ } \\
\text { Sulbactam }\end{array}$ \\
\hline 3 & 22 & Female & No & No & Thoracic & 1 Level & 246 & Yes & $\begin{array}{c}\text { Dehiscence } \\
\text { with pus }\end{array}$ & Abnormal & MRSA & $\mathrm{E}+\mathrm{R}$ & Vancomycin \\
\hline 4 & 24 & Female & No & Yes & Cervical & 1 Level & 147 & Yes & $\begin{array}{l}\text { Operation } \\
\text { site pain }\end{array}$ & Abnormal & Negative & No & $\begin{array}{r}\text { Vancomycin } \\
\text { (Empirical) }\end{array}$ \\
\hline 5 & 29 & Female & No & No & Cervical & 2 Levels & 228 & Yes & $\begin{array}{l}\text { Operation } \\
\text { site pain }\end{array}$ & Abnormal & MRSA & No & Vancomycin \\
\hline 6 & 18 & Male & No & No & Lumbar & 1 Level & 156 & Yes & $\begin{array}{c}\text { Dehiscence } \\
\text { with pus }\end{array}$ & Abnormal & E. faecium & $\mathrm{E}+\mathrm{R}$ & $\begin{array}{l}\text { Ampicillin/ } \\
\text { Sulbactam }\end{array}$ \\
\hline 7 & 64 & Male & No & Yes & Lumbar & $\begin{array}{l}\text { Multiple } \\
\text { levels }\end{array}$ & 361 & Yes & $\begin{array}{c}\text { Dehiscence } \\
\text { with pus }\end{array}$ & Abnormal & S. epidermidis & $\mathrm{E}+\mathrm{R}$ & $\begin{array}{l}\text { 1st cephalosporin / } \\
\text { vancomycin }^{+}\end{array}$ \\
\hline 8 & 67 & Male & No & Yes & Lumbar & 1 Level & 113 & No & $\begin{array}{c}\text { Dehiscence } \\
\text { with pus }\end{array}$ & Abnormal & S. epidermidis & Exploration ${ }^{\S}$ & 1st Cephalosporin \\
\hline 9 & 69 & Male & No & No & Lumbar & 1 Level & 97 & No & $\begin{array}{r}\text { Dehiscence } \\
\text { with pus }\end{array}$ & Abnormal & S. epidermidis & Exploration & 1st Cephalosporin \\
\hline 10 & 75 & Male & No & No & Lumbar & 1 Level & 88 & No & $\begin{array}{l}\text { Operation } \\
\text { site pain }\end{array}$ & Abnormal & MRSA & No & Vancomycin \\
\hline
\end{tabular}

MRSA, methicillin-resistant Staphylococcus aureus; E. faecium, Enterococcus faecium; S. epidermidis, Staphylococcus epidermidis; 1st cephalosporin, 1st generation cephalosporin.

"Abnormal laboratory findings mean the elevation of erythrocyte sedimentation rate (ESR; $>20 \mathrm{~mm} / \mathrm{hr}$ ) and C-reactive protein $\left(\mathrm{CRP} ;>0.5 \mathrm{mg} / \mathrm{dL}\right.$ ). ${ }^{+}$Patient No. 7 was injected 1st generation cephalosporin intravenously according to the culture result for the first week, but ESR and CRP values were elevated continuously. We changed 1st generation cephalosporin to vancomycin and the injection was lasting for 6 weeks, symptoms of patient and laboratory findings were improved. ${ }^{7}$ Wound exploration and implant removal were performed. ${ }^{\$}$ Only wound exploration was performed because patients had no implantation. 


\section{Statistical Analysis}

Patient demographics and the results of risk factors are summarized using means and proportions with standard deviations. Student t-test was used to compare continuous variables between groups. Pearson chi-square and Fisher exact tests were used for categorical variables to regulate differences in proportions between groups. Furthermore, odds ratios were defined where appropriate. All statistical analyses were carried out with the IBM SPSS Statistics ver. 20.0 (IBM Co., Armonk, NY, USA) and p-values less than 0.05 were considered statistically significant.

\section{RESULTS}

Two hundred eighty patients (175 men and 105 women; mean age, 53.5 years; range, 13-85 years) underwent spine surgery between October 2012 and December 2015 in our hospital and 119 patients of them applied Collatamp G in their wound before closure. Three percent of all patients (10 of 280) developed the SSI and $0.8 \%$ of patients who applied Collatamp $\mathrm{G}$ developed SSI (1 of 119). Otherwise, $5 \%$ of patients who did not apply Collatamp G developed SSI ( 9 of 161) $(p=0.034)$ in Pearson chi-square test and odds ratio was 0.143 .

Six of 10 patients with SSI showed wound dehiscence with drainage of pus and abnormal laboratory findings; elevation of ESR and CRP were noted. Wound exploration and intraoperative swab/aspiration culture were followed. The culture results of 6 patients all showed positive; Staphylococcus epidermidis (3 patients), Enterococcus faecium (2 patients), and methicillin-resistant Staphylococcus aureus (MRSA, 1 patient) were detected. Proper antibiotics were used to cure the patients for 4 to 8 weeks, and we also performed additional implant removal for 4 patients of them who had pedicle screws implantation at thoracic or lumbar level.

The other 4 patients had operation site pain without wound dehiscence but showed abnormal laboratory findings, gadolinium-enhanced MRI was followed and there were highly enhancing lesions without abscess pocket. CT guided tissue culture was performed and the culture results of 2 patients showed positive; only MRSA was detected. Empirical antibiotic therapy was performed for the other 2 patients whose culture results were negative; Vancomycin was used for intravenous injection for 4 weeks for each patient. The clinical manifestation and treatment of 10 patients with SSI are summarized in Table 1.

We also studied the correlation between SSI and other potential risk factors. We involved the following factors; age, sex, diabetes mellitus status, smoking status, operation area, operation level, operation duration, and surgical implantation (e.g., pedicle screws insertion). None of all factors had correlation with SSI, and the statistical results of risk factors including Collatamp G are summarized in Table 2.

There was no specific complications about application of
Collatamp G during wound closure, but a few minor complications were reported after injection of prophylactic antibiotics. Five patients showed mild rash and/or itching sense after injection, hydration and intravenous injection of antihistamine were followed and symptoms were diminished. All patients were given injection pre-/postoperatively without severe complication in this study.

\section{DISCUSSION}

To make a correct diagnosis of SSI is difficult in the patients without typical signs and symptoms, nor fever. Therefore, the analysis of laboratory results and image findings of gadoli-

Table 2. Patient characteristics and the statistical results

\begin{tabular}{|c|c|c|c|c|}
\hline Factor & SSI & No SSI & SUM & p-value \\
\hline Collatamp $\mathrm{G}^{+}$ & & & & 0.034 \\
\hline Yes & 1 & 118 & 119 & \\
\hline No & 9 & 152 & 161 & \\
\hline Age (yr) & & & & 0.752 \\
\hline$<65$ & 7 & 201 & 208 & \\
\hline$\geq 65$ & 3 & 69 & 72 & \\
\hline Sex & & & & 0.868 \\
\hline Male & 6 & 169 & 175 & \\
\hline Female & 4 & 101 & 105 & \\
\hline Diabetes mellitus & & & & 0.882 \\
\hline Yes & 2 & 49 & 51 & \\
\hline No & 8 & 221 & 229 & \\
\hline Smoking & & & & 1.000 \\
\hline Smoker & 3 & 81 & 84 & \\
\hline Nonsmoker & 7 & 189 & 196 & \\
\hline Operation area & & & & 0.817 \\
\hline Cervical & 3 & 107 & 110 & \\
\hline Thoracic & 1 & 20 & 21 & \\
\hline Lumbar & 6 & 143 & 149 & \\
\hline Operation level & & & & 0.854 \\
\hline 1 Level & 7 & 176 & 183 & \\
\hline 2 Levels & 2 & 74 & 76 & \\
\hline Multiple levels & 1 & 20 & 21 & \\
\hline Operation duration (min) & & & & 0.981 \\
\hline$<180$ & 6 & 161 & 167 & \\
\hline$\geq 180$ & 4 & 109 & 113 & \\
\hline Surgical implantation & & & & 0.921 \\
\hline Yes & 7 & 185 & 192 & \\
\hline No & 3 & 85 & 88 & \\
\hline Total (for each factors) & 10 & 270 & 280 & \\
\hline
\end{tabular}

SSI, surgical site infection; SUM, summation.

"The results of Pearson chi-square test for risk factors.

${ }^{+}$Collatamp G(Schering-Plough, Stockholm, Sweden). 
nium-enhanced MRI is important in those cases. After regular surgery, the CRP usually peaked at POD 2 to 3 and normalized between POD 5 to 14 . The ESR usually peaked at POD 5 to 6 but decreased at variable times after spine surgery ${ }^{11)}$. However, since these factors are sensitive but not specific, they can be elevated by any infection at any site, so we performed additional studies including chest X-ray, urine analysis, or peripheral blood culture to prevent misdiagnosis from other infections such as pneumonia, urinary tract infection, or phlebitis.

In the gadolinium-enhanced MRI studies, the infected tissues were well-distinguished from normal tissues by highly enhancing portion, and sometimes there were abscess pockets presenting low signal surrounded by infected tissues (Fig. 1). However it had a limitation when we studied patients who underwent the surgical implantation. We could not analyze the suspicious lesion due to the artifact signal caused by implantation (Fig. 2).

SSI has been revealed to add considerable cost in any countries for any kinds of surgery. In the former study by Liau et $\mathrm{al}^{6}{ }^{6}$, the mean assessed direct cost of prolonged hospital dates for each patient with SSI was expected an extra Singapore dollar 2,160 (United States dollar 1,530) per patient. Moreover, SSI also conveys substantial emotional load by distressing patient quality of life. Then, with noteworthy profits estimated from the prevention of each SSI, we expected to study if gentamicin-impregnated collagen sponge could reduce SSI rates in spine surgery.

In former studies directed on the use of Collatamp $G$ in reducing SSI in other type of surgery, Musella et al. ${ }^{8)}$ studied its use in prosthetic repair of groin hernia and determined that it was effective in decreasing SSI with $0.3 \%$ (1 of 301) in the Collatamp G group compared with 2.0\% (6 of 294) in the
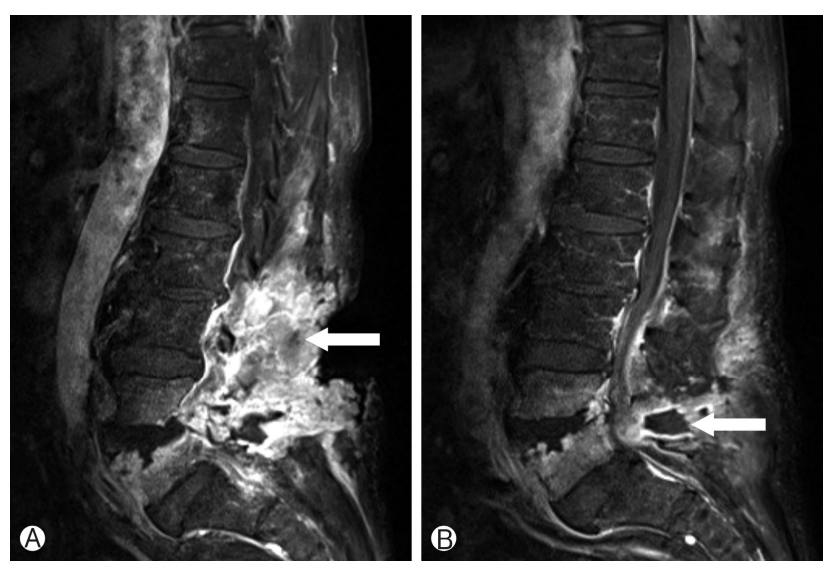

Fig. 1. Gadolinium-enhanced T1 sagittal images of lumbar magnetic resonance image. A 69-year-old male patient (No. 9 in Table 1) had surgical site infection after total laminectomy L5 and subtotal laminectomy L4. Highly enhanced infected tissues were noted at subcutaneous area (A; white arrow) and abscess pocket showed low signal surrounded by infected tissues (B; white arrow). control group ( $p=0.04$; Fisher exact test). On the other hand, Andersson et al. ${ }^{1)}$ who studied the use of Collatamp $G$ in pilonidal excision with midline suture concluded the use of Collatamp G could not improve wound healing and reduce SSI either. In their study, the SSI rate for the group with using Collatamp G was $22 \%$ (18 of 82 ) at 2-week follow-up, while the SSI rate for the control group was $26 \%(20$ of 77$)(p=0.51)$.

With these varied outcomes from former studies, we designed this study to analyze relationships not only between SSI and the use of Collatamp G, but also between SSI and other risk factors which could be possible causes of developing SSI. First, operation-related risk factors such as operation area, level, and duration were included. Operation area was divided into 3 groups by spine anatomy; cervical, thoracic, and lumbar area. Operation level was also divided into 3 groups because the number of 3 or more levels operation were too small to classify. Mean operation duration of total patients were 188.3 minutes, and mean duration of patients with SSI were 185.6 minutes, so we divided into 2 groups; duration over the 180 minutes or less. In analyzing those 3 operation-related factors stated above, they had no correlation with SSI in our data; $p=0.817$ for operation area, $p=0.854$ for operation level, and $\mathrm{p}=0.981$ for operation duration. They could be subdivided by operation techniques but we had limitations because the techniques were too many to classify in brief.

We set the surgical implantation as second risk factor to analyze relationship with SSI because foreign bodies would be significant cause of SSI and it could be classified only simple 2 divisions. However, both of these factors had no correlation with SSI in our data $(\mathrm{p}=0.921)$.

We also analyzed another well-known risk factors for SSI; Diabetes mellitus and smoking. Diabetes mellitus is an important risk factor for SSI after general surgery ${ }^{9)}$. In our study,
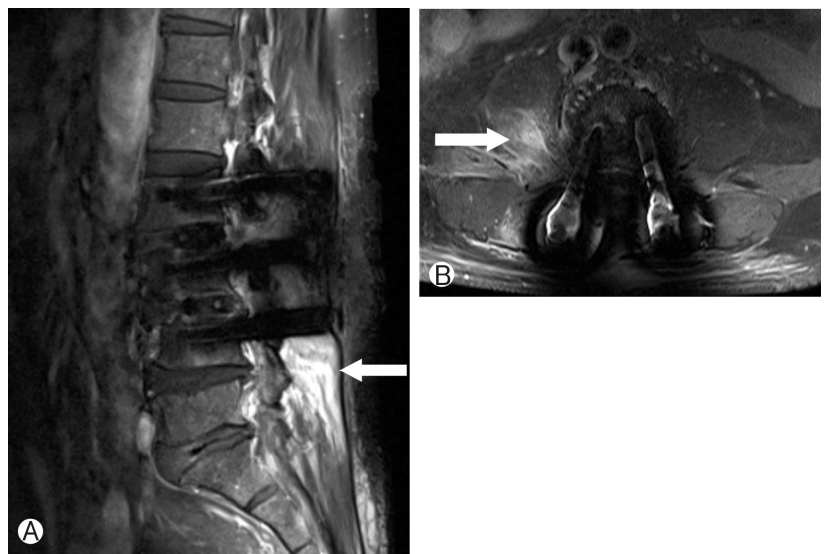

Fig. 2. Gadolinium-enhanced T1 sagittal and axial images of lumbar magnetic resonance image. A 64-year-old male patient (No. 7 in Table 1) had surgical site infection after pedicle screws fixation at bilateral L2 to L4, enhancing area was noted below the L4 level in sagittal image (A; white arrow), artifact signals interrupted analyzing subcutaneous tissues and enhancing area was only noted at right psoas muscle (B; white arrow). 
$4 \%$ of the diabetic patients developed SSI ( 2 of 51 ), and 3\% of the nondiabetic patients developed SSI (8 of 229) $(\mathrm{p}=0.882)$. Former studies have supported smoking status as another important risk factor for SSI similar to diabetes mellitus ${ }^{3,5)}$. In our study, 3\% of the smoking patients developed SSI (3 of 84 ), and also $3 \%$ of the patients developed SSI (7 of 196) $(p=1.0)$ in Pearson chi-square test and $p=0.651$ in Fisher exact test. Data of our study showed these 2 well-known risk factors had no correlation with SSI, in different with the previous studies. We supposed the reason was the number of patients with SSI in only 10, those small number of data would role as a limitation of our study. Therefore, the bigger data will be needed in the future studies. There were another limitations in our study. First, Collatamp G has $5 \times 5-\mathrm{cm}$ or $10 \times$ 10 -cm-sized sheets but we applied not only entire sheet at each cases but also partial fragments in various sizes so that gentamicin concentration could be irregular and unquantified. To minimize the limitation, the use of whole sheet or quantified fragments (e.g., an half or a quarter of the sheet) would be needed for more accurate analysis in the future studies. Second, wound class is another important factor for developing SSI, postoperative spine surgery wounds belong to cleancontaminated class in general and SSI rates is $3 \%$ to $11 \%$ according to the Centers for Disease Control and Prevention surgical wound classification ${ }^{7}$. We excluded the patients who had already infected or received spine surgery more than once, another wound class such as clean, contaminated, and dirty wounds cannot be analyzed in using Collatamp G.

\section{CONCLUSION}

Our study showed statistically significant results that SSI rate was decreased in the group of patients using Collatamp $\mathrm{G}$ in spine surgery generally, but there coexist some limitations. Collecting the bigger data of patients, focused studies for subdivided spine surgeries, and quantification of applying Collatamp $\mathrm{G}$ are required to make more accurate and reliable conclusion in the future studies.

\section{CONFLICT OF INTEREST}

No potential conflict of interest relevant to this article was reported.

\section{REFERENCES}

1. Andersson RE, Lukas G, Skullman S, Hugander A: Local administration of antibiotics by gentamicin-collagen sponge does not improve wound healing or reduce recurrence rate after pilonidal excision with primary suture: a prospective randomized controlled trial. World J Surg 34:3042-3048, 2010

2. Beiner JM, Grauer J, Kwon BK, Vaccaro AR: Postoperative wound infections of the spine. Neurosurg Focus 15:E14, 2003

3. Bryan AJ, Lamarra M, Angelini GD, West RR, Breckenridge IM: Median sternotomy wound dehiscence: a retrospective case control study of risk factors and outcome. J R Coll Surg Edinb 37:305-308, 1992

4. Griffin FA: Best-practice protocols: preventing surgical site infection. Nurs Manage 36:20, 22-26, 2005

5. Jones JK, Triplett RG: The relationship of cigarette smoking to impaired intraoral wound healing: a review of evidence and implications for patient care. J Oral Maxillofac Surg 50:237-239, 1992

6. Liau KH, Aung KT, Chua N, Ho CK, Chan CY, Kow A: Outcome of a strategy to reduce surgical site infection in a tertiarycare hospital. Surg Infect (Larchmt) 11:151-159, 2010

7. Mangram AJ, Horan TC, Pearson ML, Silver LC, Jarvis WR: Guideline for prevention of surgical site infection, 1999. Centers for Disease Control and Prevention (CDC) Hospital Infection Control Practices Advisory Committee. Am J Infect Control 27: 97-132, 1999

8. Musella M, Guido A, Musella S: Collagen tampons as aminoglycoside carriers to reduce postoperative infection rate in prosthetic repair of groin hernias. Eur J Surg 167:130-132, 2001

9. Ramos M, Khalpey Z, Lipsitz S, Steinberg J, Panizales MT, Zinner $\mathrm{M}$, et al: Relationship of perioperative hyperglycemia and postoperative infections in patients who undergo general and vascular surgery. Ann Surg 248:585-591, 2008

10. Stemberger A, Grimm H, Bader F, Rahn HD, Ascherl R: Local treatment of bone and soft tissue infections with the collagengentamicin sponge. Eur J Surg Suppl (578):17-26, 1997

11. Weinstein MA, McCabe JP, Cammisa FP Jr: Postoperative spinal wound infection: a review of 2,391 consecutive index procedures. J Spinal Disord 13:422-426, 2000

12. Yang MS, Choi BK, Lee SW, Cha SH, Song GS, Choi CH: Early phase inflammatory markers after spinal block procedures. Korean J Spine 4:146-150, 2007 